\title{
SUCCESSFUL AREA-WIDE ERADICATION OF THE INVADING MEDITERRANEAN FRUIT FLY IN THE DOMINICAN REPUBLIC
}

\author{
J. L. ZAVALA-LÓPEZ ${ }^{1}$, G. MARTE-DIAZ ${ }^{2}$ AND F. MARTÍNEZ- \\ PUJOLS ${ }^{2}$
}

\author{
${ }^{1}$ FAO/IAEA, Technical Cooperation Expert; jlzavalalopez@gmail.com \\ ${ }^{2}$ Ministry of Agriculture, Programa Moscamed-RD, Ministry of Agriculture, \\ Dominican Republic
}

\begin{abstract}
SUMMARY
The presence of the Mediterranean fruit fly Ceratitis capitata (Wiedemann) (Tephritidae) in the Dominican Republic was officially reported in March 2015. Subsequent delimitation found that the pest had already spread to $2053 \mathrm{~km}^{2}$ in the eastern part of the country, constituting a major outbreak. Trading partners imposed an immediate ban on most exports of fruit and vegetables listed as hosts of the pest, resulting in a loss of over USD 40 million over the remaining nine months of 2015. The outbreak was centred on Punta Cana, one of the busiest tourist destinations in the Caribbean. The agricultural production sites affected by the ban were more than $200 \mathrm{~km}$ away from the outbreak. The Dominican Government established the Moscamed Programme (Moscamed-RD) through its Ministry of Agriculture as an emergency response. This programme received the financial and operational support to carry out all required surveillance and control activities. The Food and Agriculture Organization of the United Nations (FAO), the International Atomic Energy Agency (IAEA), and the United States Department of Agriculture-Animal and Plant Health Inspection Service (USDA-APHIS) cooperated to assist the country in establishing a national monitoring network to determine the geographic extent of the outbreak and to initiate an eradication campaign with support from regional organizations such as the Organismo Internacional Regional de Sanidad Agropecuaria (OIRSA) and the Interamerican Institute for Cooperación on Agriculture (IICA). The regional Guatemala-México-USA Moscamed Programme played a major role in assisting through technology transfer, which included the application of the Sterile Insect Technique (SIT) and other integrated pest management components. An international Technical Advisory Committee (TAC), chaired by FAO/IAEA, provided technical oversight beginning in September 2015. The last fly was detected in January 2017 and official eradication was announced in July 2017 after six generations had passed with no detections of the pest. The Dominican Republic is now on the list of countries that have successfully eradicated the Mediterranean fruit fly and has substantially strengthened its fruit fly surveillance system and emergency response capacity.
\end{abstract} Development and Field Application, pp. 519-537. CRC Press, Boca Raton, Florida, USA. (C) 2021 IAEA 
Key Words: Ceratitis capitata, medfly, Tephritidae, Sterile Insect Technique, SIT, IPM, fruit exports, Caribbean, invasive pest

\section{INTRODUCTION}

Agriculture contributes substantially to the Dominican Republic's GDP and is the primary employer of the labour force, as well as among the main sources of foreign currency. Fruit and vegetable production and exports make up a significant portion of these benefits, including the production of avocados, bell peppers, mangoes, and tomatoes. Exotic pests and diseases present a risk to agricultural production and exports, and international phytosanitary standards recommend continuous vigilance to prevent negative impacts on this sector of the economy. The Dominican Republic experienced the repercussions of the presence of an invasive pest for which it was largely unprepared.

The incursion of Mediterranean fruit fly Ceratitis capitata (Wiedemann) into Dominican Republic was of high importance, not only for the country, but for all other countries of the Caribbean Basin that are free of this major pest. Its presence was suspected by the Dominican Republic's Ministry of Agriculture in October 2014. After accurate identification was confirmed, the detection was officially reported in March 2015. Exports of listed Mediterranean fruit fly host fruit and vegetables were banned immediately by trading partners as the lack of an operational national detection system caused uncertainty about the extent and the distribution of the pest in the country. This reduction of exports resulted in a loss of more than USD 40 million over the remaining nine months of 2015, putting some 30000 jobs at risk (Gil 2016).

\subsection{Characteristics of the Outbreak}

The outbreak was located in the Punta Cana region in the eastern Dominican Republic (Fig.1), one of the most visited tourist destinations in the Caribbean, and therefore the pest was suspected to have been brought by tourists. Delimitation trapping confirmed high densities of the pest in the coastal areas of Punta Cana and adjacent Bávaro, with sporadic detections in several contiguous provinces within the surrounding area of $2053 \mathrm{~km}^{2}$.

Fortunately, agricultural production of Mediterranean fruit fly hosts for export was non-existent in the affected area, with the major fruit and vegetable production sites affected by the ban located more than $200 \mathrm{~km}$ away from the outbreak. An additional characteristic of the outbreak was that certain known hosts, which are typically moved through commerce, such as mangos, citrus, guavas, cherries (acerola), and other host fruits common in backyards throughout the region were not attacked. Rather, larval

finds were limited to three species of wild or ornamental fruits of no agricultural importance (see Section 2.2.2.). 


\subsection{Establishment of the Moscamed Programme in the Dominican Republic}

The Government of the Dominican Republic, through its Ministry of Agriculture, responded to this emergency with the establishment of the Moscamed Programme in the Dominican Republic (Moscamed-RD), providing the required financial and operational support to perform all recommended delimitation and eradication activities.

The initial challenges were, among others: social and economic effects of the export ban; pressure of the media and private sector; answers demanded by stakeholders; questions by some on the need for eradication; mobilizing for financial and human resources; and streamlining external support, as assistance was being offered by a number of entities.

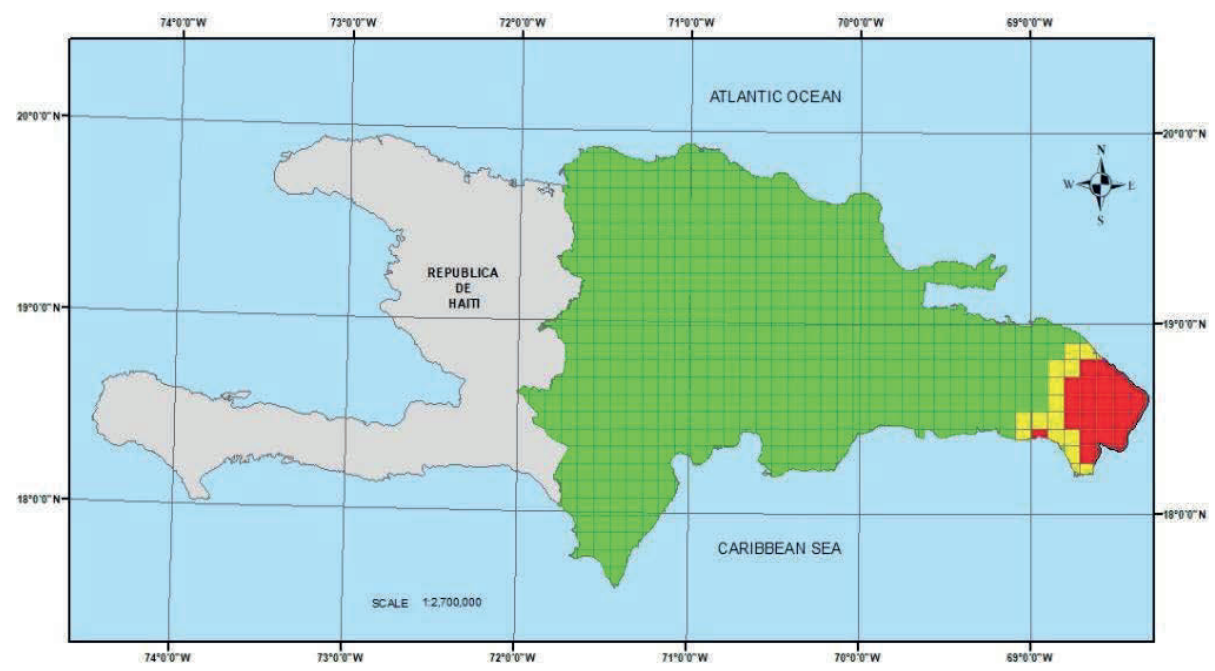

Figure 1. Map of the island of Hispaniola showing the Mediterranean fruit fly-infested area in 2015 in the eastern part of the Dominican Republic, covering parts of the provinces of La Altagracia, La Romana, San Pedro de Macorís, El Seibo and Hato Mayor (red= infested area; yellow $=$ buffer area; green $=$ free area).

The Food and Agriculture Organization of the United Nations (FAO), the International Atomic Energy Agency (IAEA), and the United States Department of Agriculture (USDA), through its Animal and Plant Health Inspection Service (APHIS), collaborated to assist the Ministry of Agriculture in establishing a national monitoring network to delimit the distribution of the outbreak and to initiate an eradication campaign. First steps were begun by USDA-APHIS, followed by a series of technical assistance and capacity building missions by the Guatemala-Mexico-USA Moscamed Programme (Enkerlin et al. 2015, 2017). 
In view of the potential devastating damage of the Mediterranean fruit fly to the Dominican Republic and neighbouring countries of the Caribbean Basin, an international coordination meeting took place in Santo Domingo in May 2015 with the participation of FAO, IAEA, regional organizations such as the Instituto Interamericano de Cooperación para la Agricultura (IICA) and the Organismo Internacional Regional de Sanidad Agropecuaria (OIRSA), as well as USDA-APHIS. The objective was to coordinate technical and financial support, as well as the supply of some critical equipment and resources. In September the technical assistance was formalized under FAO/IAEA, which established and coordinated a Technical Advisory Committee (TAC) composed of international experts.

Authorities of the Ministry of Agriculture of the Dominican Republic, with encouragement of the USDA-APHIS and the FAO/IAEA, agreed to collaborate under a Cooperative Agreement with the Moscamed Regional Programme (GuatemalaMexico-USA). The Letter of Understanding validating the agreement was signed in July 2015 taking into consideration the potential devastating damage of the Mediterranean fruit fly and the expertise available in this regional programme to help manage the pest outbreak.

This agreement facilitated not only continued training, but also equipment and supplies (some loaned or donated by USDA-APHIS) for trapping as well as the release of sterile male flies, also supplied on a cost recovery basis by the Mediterranean fruit fly mass-production facility in El Pino, Guatemala. This synergistic cooperation played a major role in assisting the Moscamed-RD Programme through technology transfer of all components of an area-wide integrated pest management (AW-IPM) approach that included the Sterile Insect Technique (SIT) as a major component in the final eradication phase (Dyck et al. 2021).

\section{DELIMITATION OF OUTBREAK AND PREPARATORY ACTIVITIES}

The eradication process followed during the 2015-2017 campaign, which is broadly summarized in Fig. 2, included these phases and actions:

\subsection{Preparatory Pre-eradication Phase}

Immediately after reporting the detection of the Mediterranean fruit fly in the eastern part of the Dominican Republic, trade restrictions were imposed on the export of Dominican fruit and vegetable host material. This was mainly due to the absence of a solid operational trapping network and resulting uncertainty about the geographic distribution of the pest.

Through the above-mentioned Cooperative Agreement, technology transfer and capacity building efforts were strengthened, and training of Moscamed-RD personnel continued in subjects such as detection, identification (taxonomic as well as sterile vs. wild), pest suppression and eradication, public relations, quarantine and other activities related to the implementation of AW-IPM programmes. 


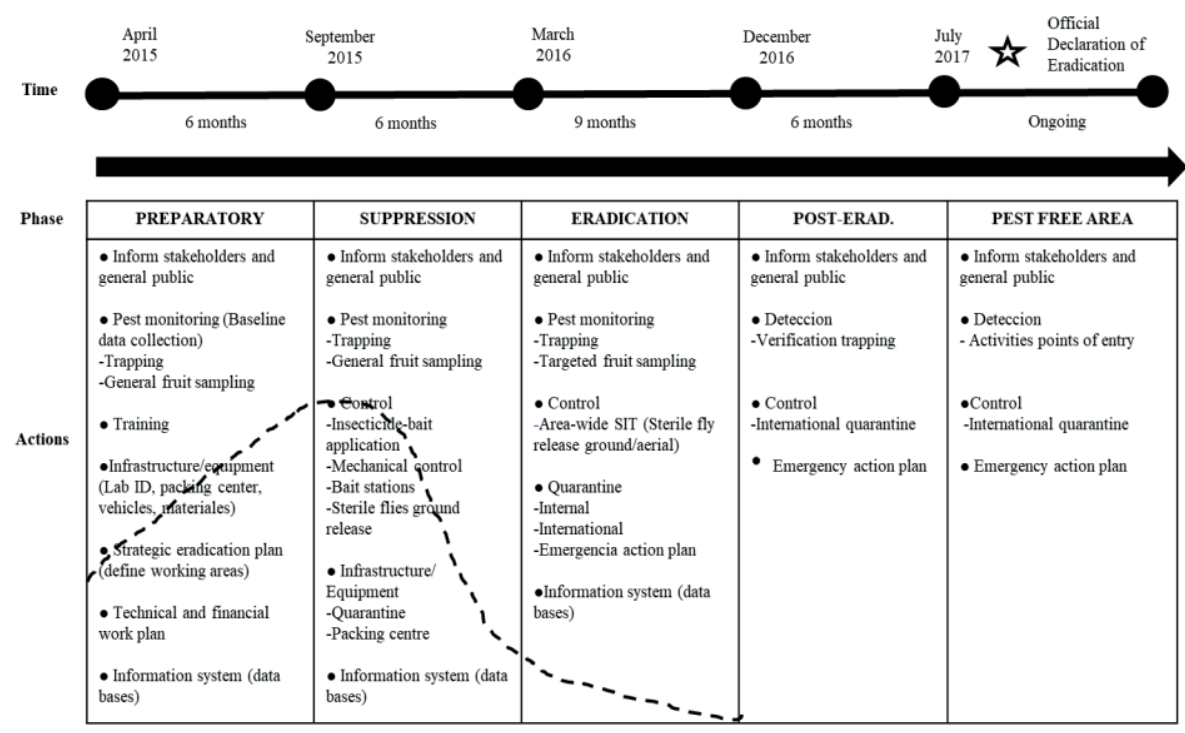

Figure 2. Phases and actions of the eradication process followed during the Mediterranean fruit fly eradication campaign 2015-2017 in the Dominican Republic (dotted line is a theoretical representation of population density) (source Walther Enkerlin, FAO/IAEA Insect Pest Control Section).

The detection system was gradually enhanced from the original limited and occasional trapping to an effective national surveillance system. Trap types used included Jackson traps baited with the male-attractant trimedlure, the female-biased Phase IV traps baited with the synthetic food lure Biolure, and Multilure traps baited with the more generic liquid protein baits such torula yeast and Ceratrap.

The trapping network during the preparatory or pre-eradication phase rapidly expanded from 1006 traps, mainly at points of entry (every two weeks with inspection levels of only about $25 \%$ of traps), to 14589 traps country-wide (9936 male-specific Jackson traps and 4653 female biased Phase IV traps) that remained in place during 2015 (Table 1 and Fig. 3).

The country-wide trapping reached inspection levels of over $95 \%$ (weekly in the buffer and infested areas, or every two weeks in the Mediterranean fruit fly-free areas and points of entry).

Trapping and fruit sampling were significantly increased in the eastern region, aimed at accurately determining the distribution and potential spread of the infestation, locating any remnants of the infestation that may have been missed, as well as enabling sound decision-making and planning of suppression and eradication activities. The majority of traps in the country, 64\% (or 9936 traps) were placed in the eastern region, where the initial detection occurred, consisting of 4687 Jackson Traps and 5249 food-based traps (Fig. 4). 
Table 1. Maximum number of traps in the national Mediterranean fruit fly trapping network established in 2015 in the Dominican Republic

\begin{tabular}{|l|c|c|c|c|c|c|c|}
\hline $\begin{array}{c}\text { Traps/ } \\
\text { Attractant }\end{array}$ & $\begin{array}{c}\text { La Alta- } \\
\text { gracia }\end{array}$ & $\begin{array}{c}\text { La } \\
\text { Romana }\end{array}$ & $\begin{array}{c}\text { El } \\
\text { Seibo }\end{array}$ & $\begin{array}{c}\text { Hato } \\
\text { Mayor }\end{array}$ & $\begin{array}{c}\text { San } \\
\text { Pedro de } \\
\text { Macorís }\end{array}$ & $\begin{array}{c}\text { Rest of } \\
\text { Domi- } \\
\text { nican } \\
\text { Republic }\end{array}$ & Total \\
\hline $\begin{array}{l}\text { Jackson/ } \\
\text { Trimedlure }\end{array}$ & 2797 & 363 & 605 & 476 & 446 & 5249 & 9936 \\
\hline $\begin{array}{l}\text { Phase IV/ } \\
\text { Biolure }\end{array}$ & 3015 & 430 & 577 & 372 & 259 & 0 & 4653 \\
\hline Total & 5812 & 793 & 1182 & 848 & 705 & 5249 & 14589 \\
\hline
\end{tabular}

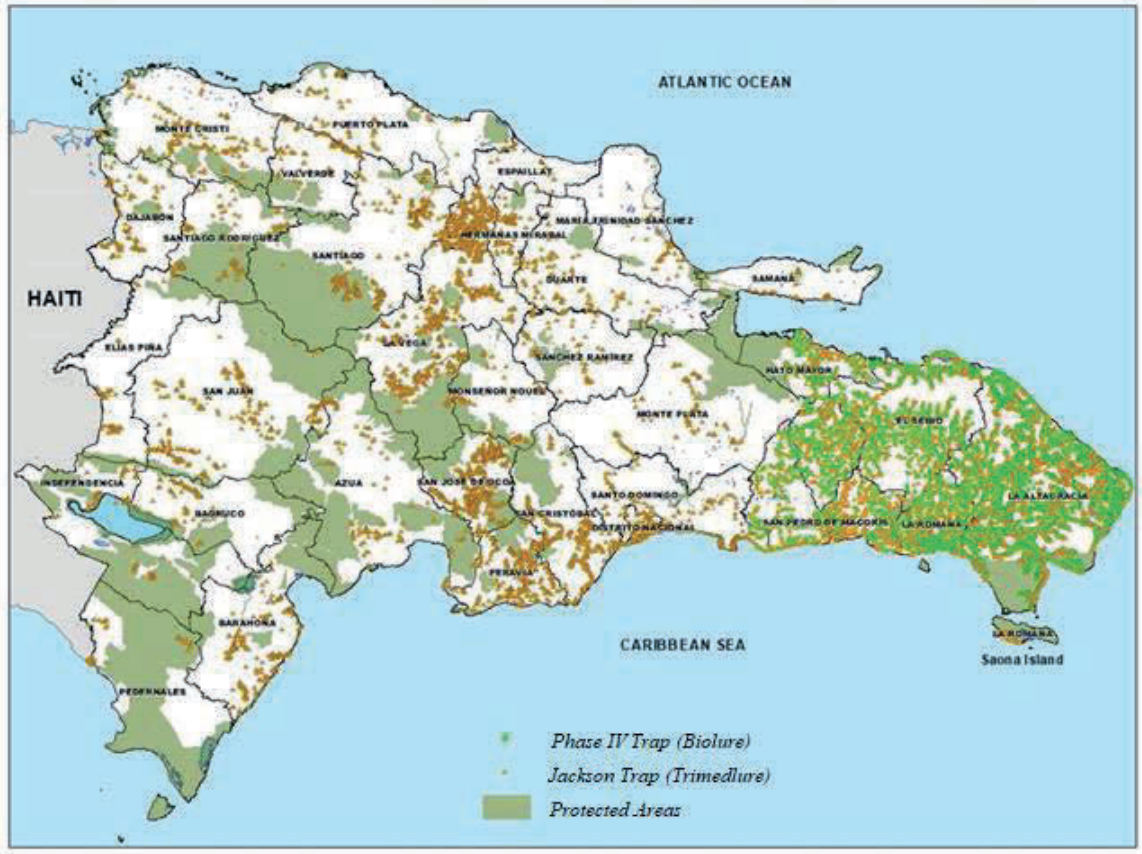

Figure 3. National Mediterranean fruit fly trapping network established in 2015 in the Dominican Republic (yellow triangles $=$ Jackson traps, green circles $=$ Phase IV/Biolure traps). 


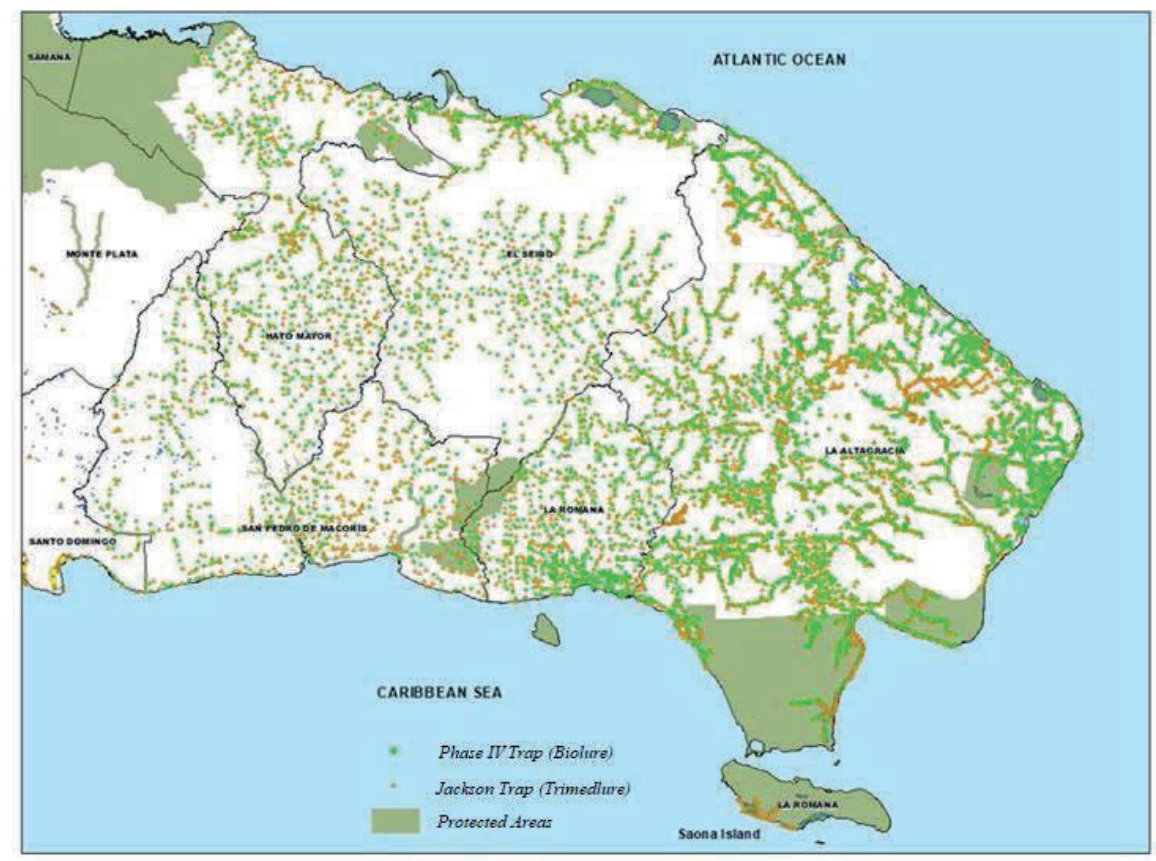

Figure 4. Trapping network in the eastern region of the Dominican Republic (yellow triangles $=$ Jackson traps, green circles $=$ Phase IV/Biolure traps).

During this preparatory phase, fruit sampling activities followed a general approach, systematically collecting a wide range of soft-skinned fruit species that could potentially be susceptible to Mediterranean fruit fly infestation. A total of 10589 fruit samples were collected and dissected. Once the host range had been assessed for the Dominican Republic, a targeted stratified sampling protocol was implemented as explained in Section 2.2.2. (FAO/IAEA 2017a, and FAO/IAEA 2018).

The results of the surveillance system indicated that the infestation was concentrated in and around the coastal touristic areas of Punta Cana and Bávaro, with sporadic wide-spread detections throughout the eastern provinces. Most adult (1572) and immature stages of the fly (1189 larvae in 225 infested samples) were found in the 8 weeks after initial activities were begun in March 2015. The pest was found not only in the Punta Cana and Bávaro area, but later also in other areas in the Province of La Altagracia, and subsequently also in the nearby provinces of El Seibo, San Pedro 
Macorís, and Hato Mayor (see Fig. 7). A reproducing and recurring population was also found in a popular tourist area in the Province of La Romana.

The group of international experts commissioned by the FAO/IAEA under the external TAC first met on-site in January 2016 and reviewed activities and results so far achieved during the initial months of the programme. The TAC confirmed that eradication was still feasible and recommended that an area-wide programme be established, integrating the SIT, as the core eradication activity, with other control methods.

The cooperation with several stakeholders, in particular experts from the Guatemala-México-USA Moscamed Programme and the FAO/IAEA, as well as the recommendations of the TAC (September 2015, January 2016, October 2016 and July 2017), served to guide the implementation of all activities and provide continuous technical back-stopping.

\subsection{Suppression and Eradication Phase}

The new surveillance system (trapping and fruit sampling) allowed the programme to develop and implement the strategies for the immediate suppression and ultimate eradication of the established Mediterranean fruit fly populations.

\subsubsection{Detection - Trapping Networks}

The goal during this suppression phase was a trap density of 2 traps per $\mathrm{km}^{2}$ at a $1: 1$ ratio (Jackson trap to Phase IV/Multilure trap) in areas with host presence, as well as achieving high trap servicing levels (Fig. 5). Once the SIT was initiated, the trap ratio was adjusted in release areas to a 1:9 ratio to focus on wild female detection and to minimize sterile male recapture. Trap service intervals were changed to once every two weeks in the Mediterranean fruit fly-free areas and remained at once per week in the infested and buffer areas of the eastern region (Fig. 5).

For each Mediterranean fruit fly find, a high-density delimitation trapping was installed in a $9 \mathrm{~km}^{2}$ area around the find for three life cycles, as indicated by international trapping protocols (FAO 2016).

Once the infestation on the island was well delimited and aerial sterile fly releases initiated in 2016, the total number of traps in the Mediterranean fruit fly-free areas of the eastern region was gradually reduced to allow concentrating more of the available resources on areas with suppression/eradication activities.

Overall, there was no real trapping network in the first quarter of 2015, and from 5 April 2015 to 14 January 2017, 4174 adults (3938 males and 236 females) were caught in 594 traps out of a total of 14589 traps deployed country-wide. Adult detections were higher during the second and third quarter of the year, both in 2015 and 2016 (Fig. 6). 

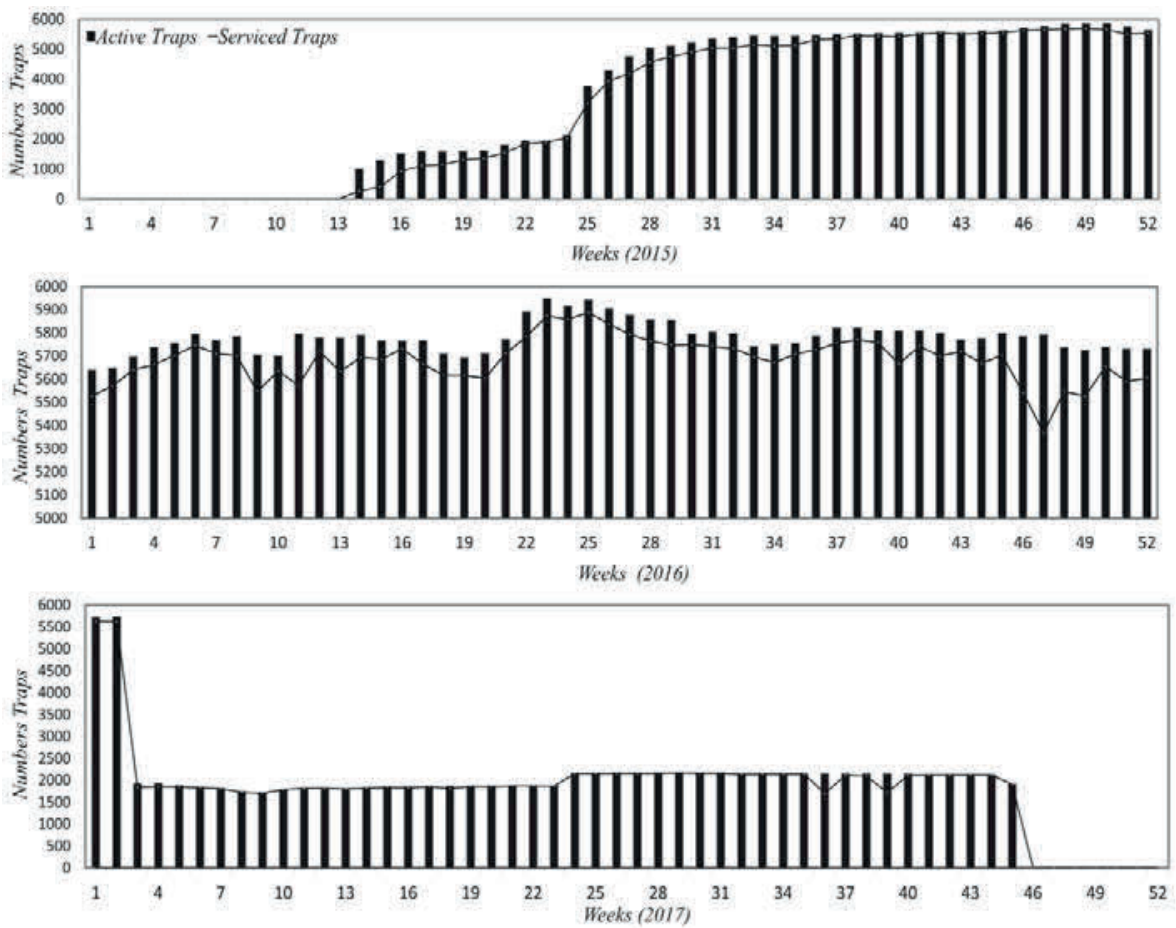

Figure 5. Numbers of installed traps (solid bars) and servicing levels of these traps (line) in the eastern region, including La Altagracia Province, during the 2015-2017 eradication campaign.

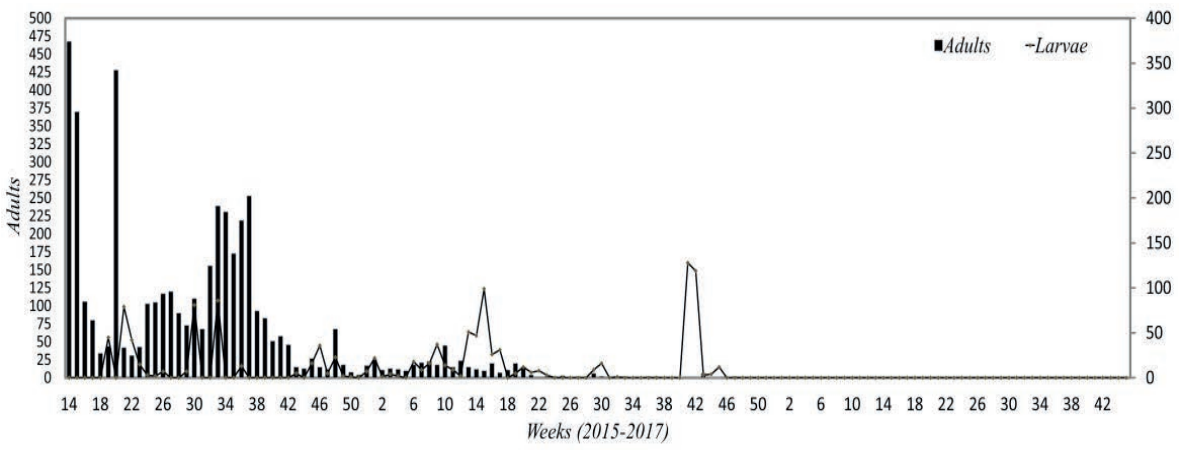

Figure 6. Numbers of detected wild adult flies (black bars) and larvae (line) of Ceratitis capitata per week during the 2015-2017 eradication campaign in the eastern region of the Dominican Republic. 
The trapping network also provided valuable information on the spatial distribution of the pest, clearly showing that the population was concentrated on the eastern part of the country, mainly within the La Altagracia Province, with the highest numbers present in Punta Cana where the epicentre of the outbreak was located (Fig. 7). A second, incipient outbreak was also found in the Province of La Romana.

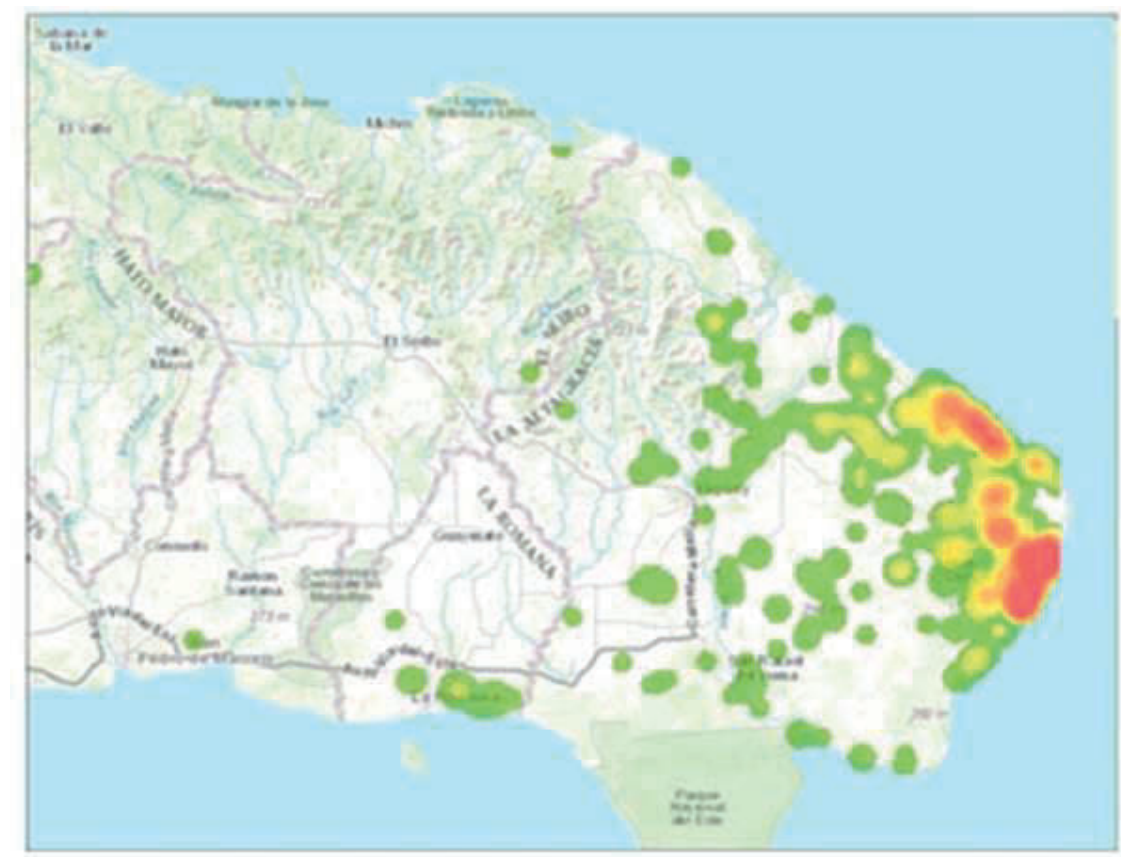

Figure 7. Locations where all Mediterranean fruit flies were captured in the Dominican Republic between 2015 and 2017 in the Provinces of La Altagracia, La Romana, El Seibo, Pedro de Macoris, and Hato Mayor. Colours represent the absolute numbers of wild fly detections per location (green dot =1-2 flies; yellow = 3-5 flies; orange $=10$ to 25 flies; red $=$ $>150$ flies).

\subsubsection{Detection - Fruit Sampling}

As was done for the trapping, fruit sampling was adjusted during this phase to mainly target or direct sampling to the confirmed hosts. The general fruit sampling data indicated 95 infested samples of tropical almond Terminalia catappa L. and 19 infested samples of yellow caya Sideroxylon foetidissimum Jacq., locally known as "yellow caya" which therefore were the major C. capitata hosts, though larvae were also found in three samples of another wild host Simarouba berteroana Krug \& Urb, locally known as "aceitunas = olives" or "black caya", with 3 infested samples. Based on this information, fruit sampling efforts in the infested area were mainly targeted to these three host species to increase the probability of detection. 
Overall, 1189 larvae were detected in 10589 fruit samples with a total mass of $34789 \mathrm{~kg}$ of fruits. Consistent with the trapping results, the majority of larvae were detected during the second and third quarter of the year, both in 2015 and 2016 (Fig. 8 ). This figure shows that the peak infestation occurred during week 21 of the year 2015 with an average of 7.4 larvae per sample, although the highest number of larvae was obtained in week 41 of 2016 in a large localized infestation in the Bávaro area. The last larva was detected in week 46 of 2016.

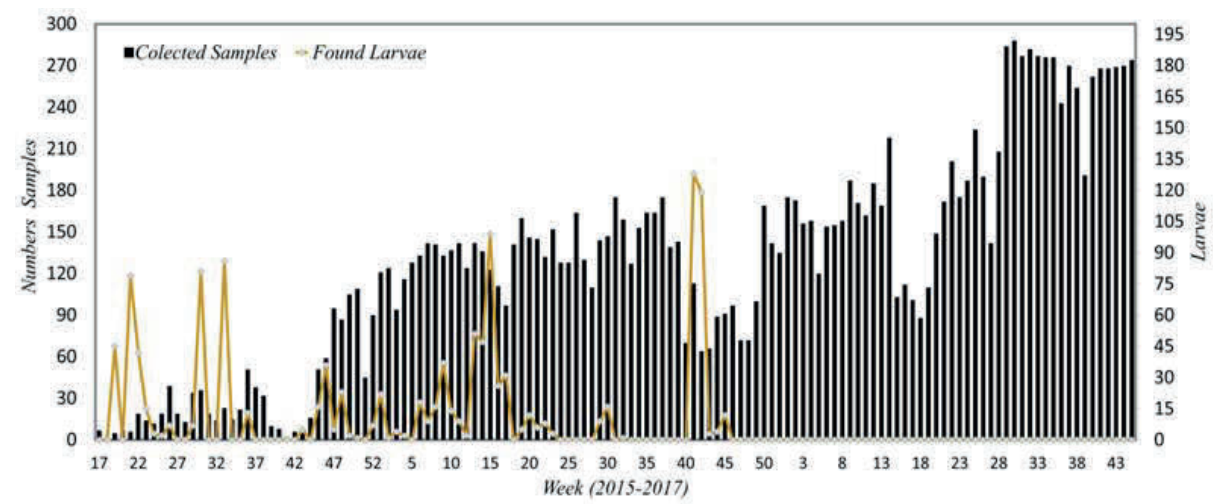

Figure 8. Numbers of fruit samples collected (black bars) and Mediterranean fruit fly larvae detected (brown line) during 2015-2017.

\subsubsection{Mechanical/Cultural Control}

Mechanical/cultural control consisted of the collection and disposal of C. capitata host fruit (on the ground and in the tree), as well as the elimination or severe pruning of host trees, mainly tropical almond, yellow caya and black caya, in the infested areas. A total of 1200 tons of fruit were collected and destroyed, mainly from tropical almond and yellow caya (Fig. 9).

\subsubsection{Bait Spray Application}

Bait sprays were mainly applied by ground to an area of one square kilometre surrounding hot spots (where repeated detections were made) in 2016 and 2017, although limited aerial bait spraying was also carried out in hot spot areas in 2015 (Fig. 10).

In addition, three scenarios for the aerial application of bait spray were proposed in preparation for the first quarter of 2016 in case of an increase in detections during the March-May period:

a) application of the bait spray on 32241 ha, which covered all accumulated outbreaks,

b) only on 4342 ha, which covered active outbreaks, and

c) only on 1883 ha, which covered outbreaks from the last 4 weeks. 
Due to reasons beyond the control of the programme, such as inadequate supply of GF-120, arrival of a large tourist population for Easter, and the socio-political situation in the area, it was not possible to carry out the aerial bait sprays as planned to expedite the eradication process.

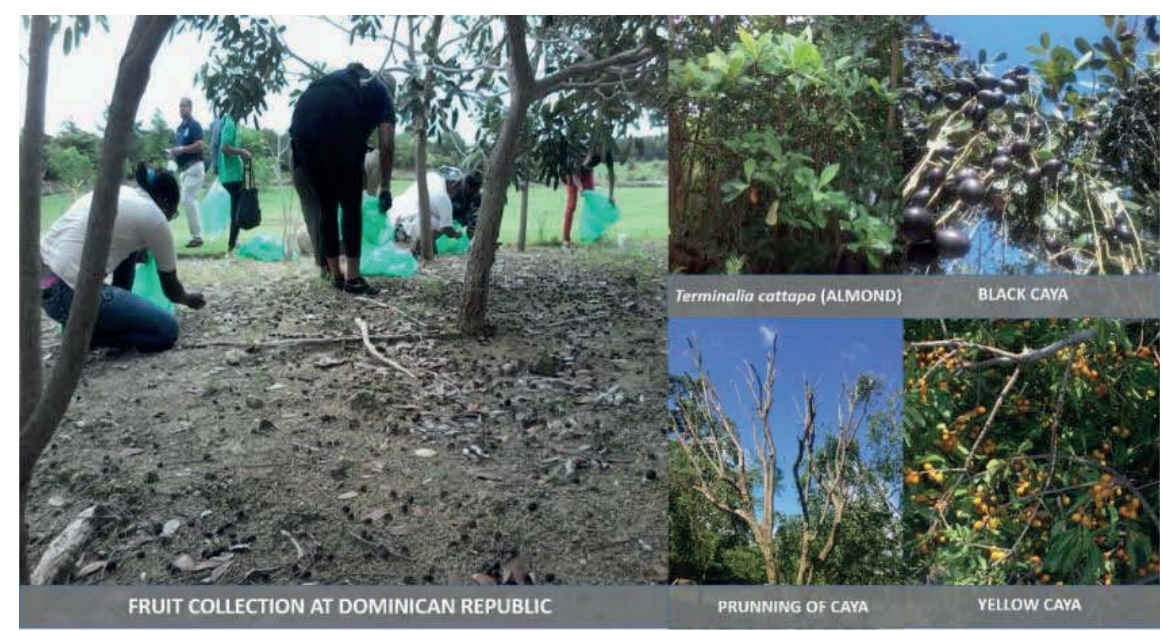

Figure 9. Mechanical /cultural control activities consisting of the destruction of host fruit and the pruning or elimination of wild hosts in the infested area.

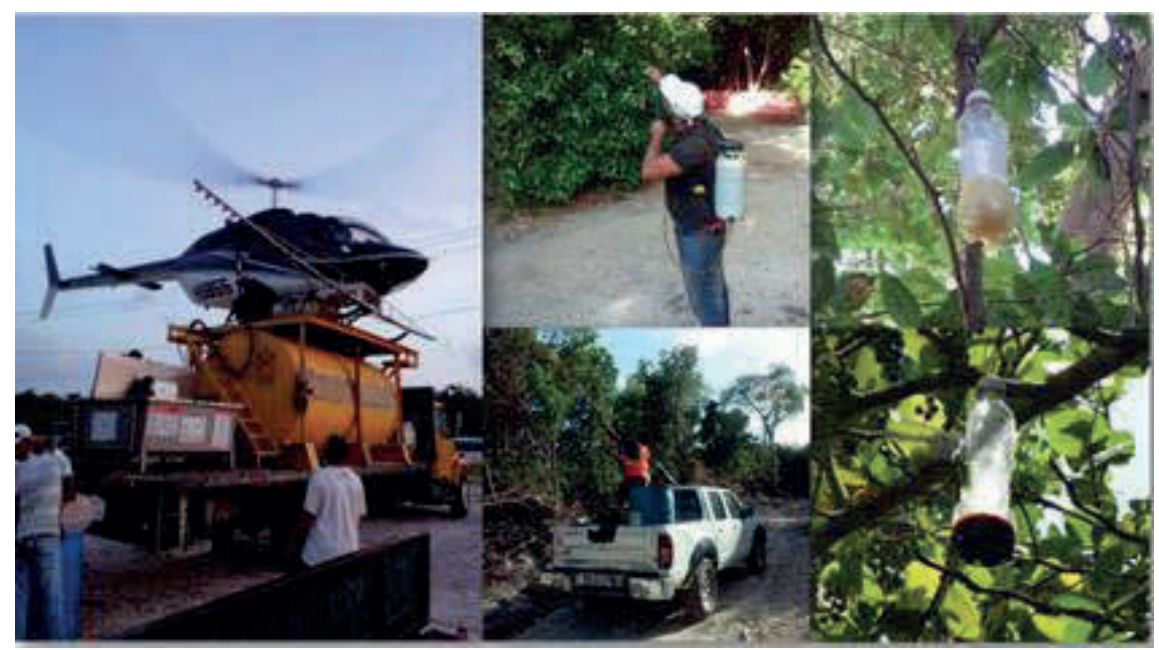

Figure 10. Aerial and ground insecticide-bait spray activities and placement of bait stations. 


\subsubsection{Bait Stations}

Bait stations were used as part of the AW-IPM approach to support the ground sprays within the one square kilometre core area of the delimitation trapping area and to cover some locations outside of the core area (Piñero et al. 2014). They were used as a complement when the infested area could not be sprayed, where there was a lack of host trees to be treated, in the surrounding areas in cases of dense vegetation that was difficult to penetrate, and also when ground sprays were ineffective because of the heavy rains.

In total 28176 stations baited with Ceratrap, 21133 stations baited with GF-120, and 1513 prototype bait stations developed in Guatemala were installed in areas neighbouring outbreaks (Fig. 10). They were also used as a preventive measure in areas where larvae had been detected in fruit.

\subsubsection{Quarantine and Exclusion Activities}

A network of quarantine road stations was placed strategically on the main highways and exit points from the La Altagracia Province to prevent the movement of the pest through infested fruit to Mediterranean fruit fly-free areas (Fig. 11).

Apart from the internal quarantine stations, inspection at international points of entry was upgraded due to the large number of tourists (ca. 5 million per year) visiting the country. X-ray machines were installed at seaports and airports, with particular attention to the Punta Cana and La Romana airports. Careful supervision of exclusion activities at these points of entry continues to be crucial to prevent new fruit fly incursions into the country in consignments or in passenger luggage.

\subsubsection{Sterile Insect Technique}

Sterile male fly releases began in October 2015 after the Mediterranean fruit fly infestation was delimited and the populations in hot spots suppressed. For the first six months, the flies were emerged in paper bags and released by ground, beginning with 1 million pupae per week, increasing gradually to 15 million per week. Aerial release of sterile flies was initiated in March 2016, using the chilled adult release system following an area-wide approach in release blocks (FAO/IAEA 2017b). An existing Ministry of Agriculture building in Higuey (one-hour drive to the airport) was adapted to host the fly emergence and release facility. A cold room was installed adjacent in the facility and an average of 72 million good quality sterile male flies were emerged, chilled, packed and released each week (average of $82.1 \%$ of emergence, $91.7 \%$ flight ability and 87.3 absolute fliers).

The sterile flies were distributed by air over eight release blocks or polygons, covering a total of 42000 ha in the provinces of La Altagracia and La Romana (Barclay et al. 2016; FAO/IAEA/USDA 2019). The total number of sterile males released throughout the campaign was 4062 million. USDA chilled release machines (single-box) were loaned to the programme from the APHIS Aircraft and Equipment Operations facility in Edinburg, Texas. Each machine was installed in a Beechcraft King Air 90 and loaded with a single $1 \mathrm{~m}$ tall release box with a maximum capacity of 14 million sterile medflies per flight. 


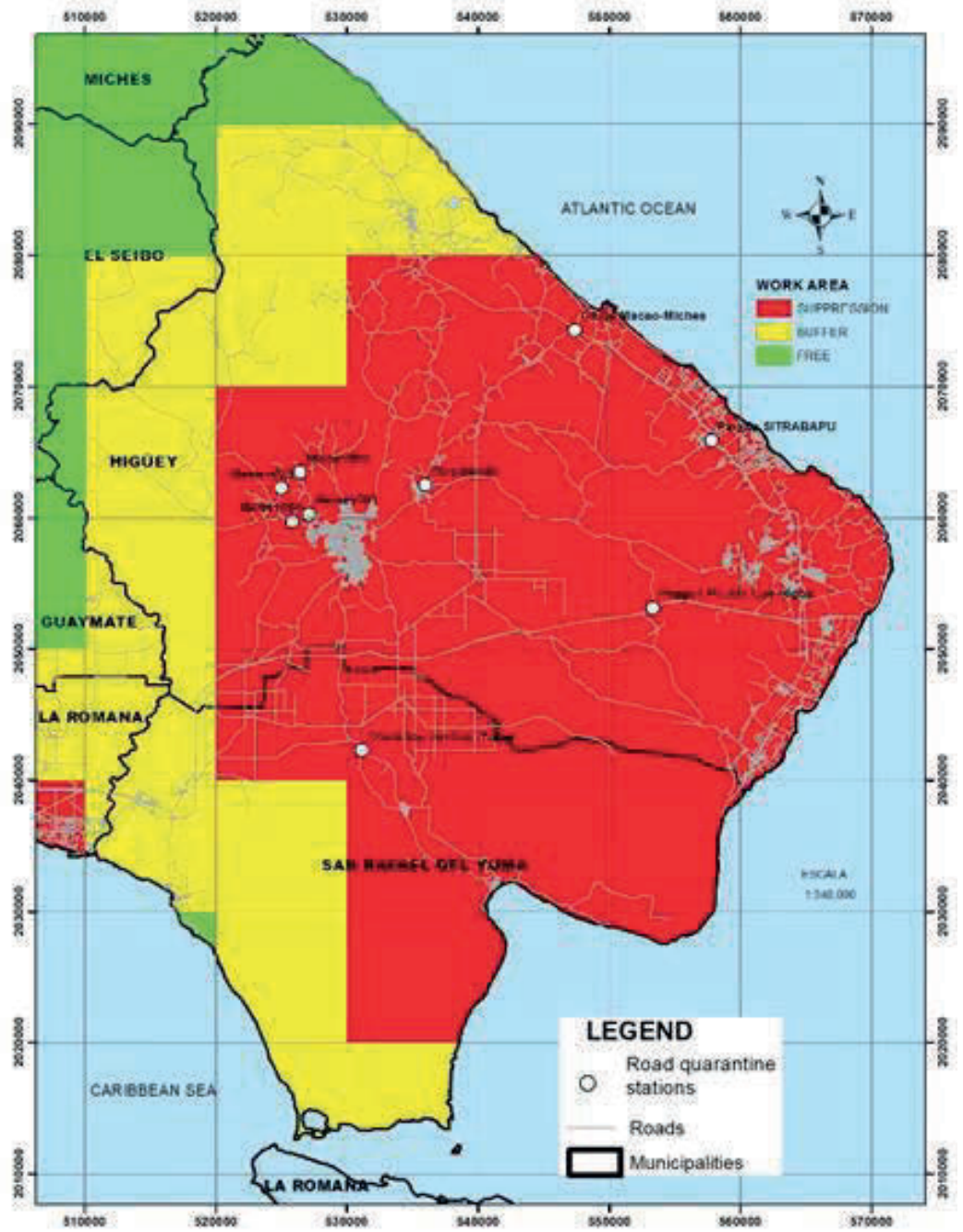

Figure 11. Distribution of road quarantine stations in the eastern part of Dominican Republic during the Mediterranean fruit fly eradication phase.

The distribution of the recaptured sterile flies (\% traps with at least one capture) averaged $60 \%$, which is below the recommended level of $85 \%$. Release blocks located along the coastline were affected by strong dominant winds from the east, likely causing sterile fly drift (Fig. 12). Therefore, 15 million additional sterile male flies were released weekly by ground, on average, along the coast of Bávaro, Punta Cana and La Romana to achieve effective sterile to wild fly ratios in the main outbreak areas. Blocks showing low sterile fly distribution were further reinforced through ground releases specifically focussed on detection and outbreak sites. 


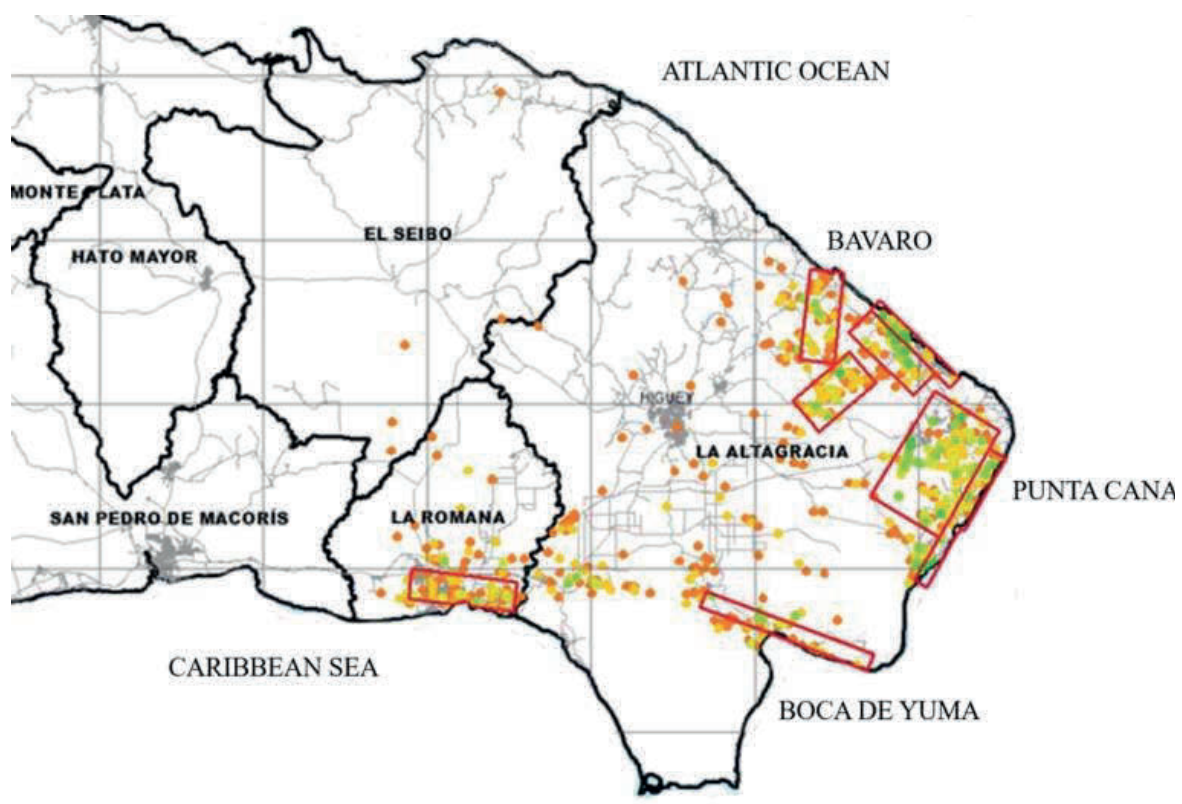

Figure 12. Blocks of aerial and ground release of sterile flies and example of average sterile fly recapture in a week (red dot $=0-1$ sterile fly; orange $=2-5$; yellow $=6-10$ sterile flies; light green $=11-25$ sterile flies; green $=>26$ sterile flies $)$.

The last fertile adult Mediterranean fruit fly was detected the second week of January 2017 after less than two years of beginning intensive control measures against the pest (Programa Moscamed-RD 2017). In May 2017, sterile releases were suspended once three fly generations had passed since the last wild fly catch, which was equivalent to at least 12 weeks or ca. 3 fly generations of zero catches after the last detection.

\subsection{Post-Eradication Phase}

Following another risk mapping analysis at the end of 2016, a further re-arrangement of the trapping network was carried out. The total number of traps in service was reduced to a total country-wide of 4630 in early 2017, of which 2835 were deployed in the eastern region and 1795 in the rest of the country (Fig. 5 and Table 2). In addition, Phase IV traps were replaced by Multilure and McPhail traps baited with torula yeast in view of their better performance under the conditions of the Dominican Republic. 
In addition, verification trapping was conducted during the post-eradication phase after sterile male releases were terminated. Verification trapping implies that traps were placed at a higher density $\left(5 / \mathrm{km}^{2}\right)$ in areas where infestations had previously been confirmed. More sensitive traps such as C\&C (Cook \& Cunningham) and yellow panel traps (Programa Regional Moscamed 2012) were included in the verification trapping (FAO/IAEA 2018). This was implemented in May-June 2017 as a final confirmation to support official declaration of eradication in July 2017, and then continued through October 2017 at the request of USDA-APHIS.

Table 2. Number of traps deployed in the relevant provinces in 2017 after the risk analysis

\begin{tabular}{|c|c|c|c|c|c|c|c|}
\hline $\begin{array}{c}\text { Traps } \\
\text { (Attractant) }\end{array}$ & $\begin{array}{c}\text { La } \\
\text { Altagracia }\end{array}$ & La Romana & $\begin{array}{c}\text { El } \\
\text { Seibo }\end{array}$ & $\begin{array}{c}\text { Hato } \\
\text { Mayor }\end{array}$ & $\begin{array}{c}\text { San Pedro } \\
\text { de Macorís }\end{array}$ & $\begin{array}{c}\text { Rest of } \\
\text { Domi- } \\
\text { nican } \\
\text { Republic }\end{array}$ & Total \\
\hline $\begin{array}{c}\text { Jackson } \\
\text { (Trimedlure) }\end{array}$ & 734 & 204 & 75 & 56 & 123 & 1730 & 2922 \\
\hline $\begin{array}{c}\text { Mc Phail } \\
\text { (Torula yeast) }\end{array}$ & 656 & 0 & 0 & 0 & 0 & 65 & 721 \\
\hline C\&C & 0 & 22 & 0 & 0 & 0 & 0 & 22 \\
\hline Yellow Panel & 0 & 11 & 0 & 0 & 0 & 0 & 11 \\
\hline $\begin{array}{c}\text { Multilure } \\
\text { (Ceratrap) }\end{array}$ & 489 & 201 & 79 & 72 & 113 & 0 & 954 \\
\hline Total & 1879 & 438 & 154 & 128 & 236 & 175 & 4630 \\
\hline
\end{tabular}

As a result of the successful implementation of the programme, the export ban for horticultural products in most western and central areas of the country was lifted in early 2016, only 9 months after intensive surveillance and suppression activities were begun. USDA-APHIS lifted the export ban for 23 provinces in January 7, 2016 and later for another 2 provinces in August 10, 2016.

The benefits of the programme in confining the invading pest to the eastern part of the country, which allowed opening some export markets, and then achieving eradication in early 2017 were immediate, with exports nearly recovering to preoutbreak levels in 2016, and even significantly increasing in 2017 (Fig. 13).

Now that Mediterranean fruit fly has been eradicated, a reliable surveillance network is being maintained to detect future C. capitata and other fruit fly populations early, and trained personnel and supplies are in place to provide a rapid response to any future detection or outbreak.

International quarantines and trapping at ports of entry, suitable host areas, tourist sites, markets and those locations where pest presence was recurrent during the outbreak are also being strengthened to protect the Mediterranean fruit fly-free status and prevent further introductions. 


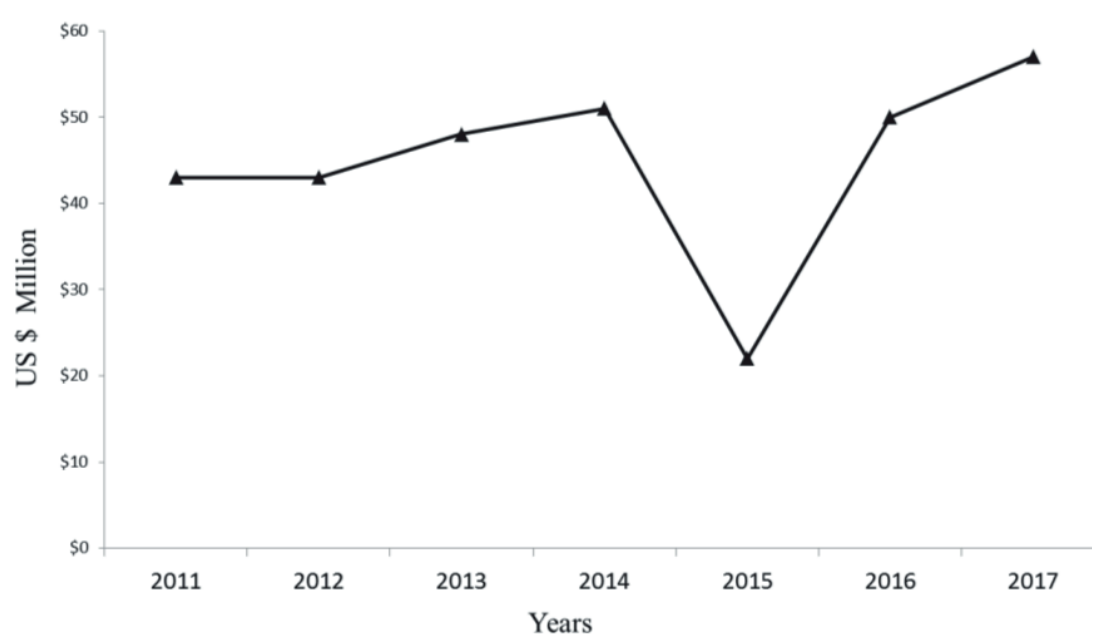

Figure 13. Exports of horticultural products from the Dominican Republic to the USA between 2011 and 2017, including the export ban in March 2015 because of the Mediterranean fruit fly invasion.

\section{CONCLUSIONS}

The last adult Mediterranean fruit fly was detected in the Dominican Republic in the second week of January 2017. Eradication of the pest from the Dominican Republic using an IPM approach including area-wide SIT application was confirmed in April 2017 after a period of at least three full life cycles with zero captures. Nevertheless, the official declaration of eradication took place in July 2017 after six generations of zero catches and an additional verification trapping network established in high risk areas, including previous detection sites. These additional detection efforts confirmed the absence of the pest.

Most importantly, the country has strengthened its quarantine procedures and developed the capacity for early detection and emergency response for invasive fruit fly pest incursions, as well as for area-wide application of the SIT. This valuable experience can now be shared with Haiti and other countries throughout the Caribbean region to strengthen their quarantine and surveillance systems for invasive fruit flies and other pests, and to prevent similar situations, which can result in serious economic and social losses for the whole region.

The Dominican Republic is now on the list of countries that have successfully eradicated the Mediterranean fruit fly, along with Chile, Mexico, and the USA, and others that have established Mediterranean fruit fly-free areas including Argentina, Australia, Guatemala and Peru on the American continent. 
In view of the experience, the Dominican Republic has established a National Fruit Fly Programme with an assigned annual budget to maintain the gained expertise, manage native Anastrepha fruit flies, and maintain the surveillance and response capacities for invasive fruit flies and other pests.

\section{ACKNOWLEDGEMENTS}

The authors wish to acknowledge the highly qualified technical staff of the Moscamed Programme of the Governments of Guatemala, Mexico and the USA that played a major role in the transfer and area-wide implementation of the Sterile Insect Technique in the Dominican Republic.

Also, our appreciation of the valuable contributions of Walther Enkerlin, Jorge Hendrichs, Don McInnis, David Midgarden, Pedro Rendón, Jesus Reyes, and Ricardo Rodriguez, members of the Technical Advisory Committee that provided technical and strategic guidance throughout the eradication process.

Important in-kind contributions of national and international organizations including FAO, IAEA, IICA, OIRSA and USDA are also acknowledged. Our thanks to Jorge Melvin Arias from the Programa Moscamed-RD for the compilation and analysis of data. The valuable assistance improving an earlier version of the manuscript by David Midgarden, and in editing of figures and graphs by Alberto Gonzalez Lara from the Moscamed Programme in Mexico, is also acknowledged.

\section{REFERENCES}

Barclay, H. J., R. Steacy, W. Enkerlin, and P. den Driessche. 2016. Modelling diffusive movement of sterile insects released along aerial flight lines. International Journal of Pest Management 62: 228-244.

Dyck, V. A., J. Hendrichs, and A. S. Robinson (eds.). 2021. Sterile Insect Technique - Principles and practice in Area-Wide Integrated Pest Management. Second Edition. CRC Press, Boca Raton, Florida, USA. $1200 \mathrm{pp}$.

Enkerlin, W. R., J. M. Gutiérrez-Ruelas, A. Villaseñor-Cortés, E. Cotoc-Roldán, D. Midgarden, E. Lira, J. L. Zavala-López, J. Hendrichs, P. Liedo, and F. J. Trujillo-Arriaga. 2015. Area freedom in Mexico from Mediterranean fruit fly (Diptera: Tephritidae): A review of over 30 years of successful containment program using an integrated area-wide SIT approach. Florida Entomologist 98: 665-681.

Enkerlin, W. R., J. M. Gutiérrez Ruelas, R. Pantaleón, C. Soto-Litera, A. Villaseñor-Cortés, J.L. Zavala-López, D. Orozco-Dávila, P. Montoya-Gerardo, L. Silva-Villarreal, E. Cotoc-Roldán, F. Hernández-López, A. Arenas-Castillo, D. Castellanos-Domínguez, A. Valle-Mora, P. RendónArana, C. Cáceres-Barrios, D. Midgarden, C. Villatoro-Villatoro, E. Lira-Prera, O. ZelayaEstradé, R. Castañeda-Aldana, J. López-Culajay, P. Liedo-Fernández, G. Ortíz-Moreno, J. Reyes-Flores, and J. Hendrichs. 2017. The Moscamed regional programme: A success story of areawide Sterile Insect Technique application. Entomologia Experimentalis et Applicata 164: 188-203.

(FAO) Food and Agriculture Organization of the United Nations. 2016. Requirements for the establishment and maintenance of pest free areas for tephritid fruit flies. International Standard for Phytosanitary Measures (ISPM) 26. International Plant Protection Convention, Rome, Italy.

(FAO/IAEA/USDA) Food and Agriculture Organization/International Atomic Energy Agency/United States Department of Agriculture. 2019. Product quality control for sterile massreared and released tephritid fruit flies. Version 7.0. International Atomic Energy Agency, Vienna, Austria. 148 pp. 
(FAO/IAEA) Food and Agriculture Organization/International Atomic Energy Agency. 2017a. Fruit sampling guidelines for area-wide fruit fly programmes. W. R. Enkerlin, J. Reyes-Flores, and G. Ortiz (eds.). Food and Agriculture Organization of the United Nations. Vienna, Austria. 45 pp.

(FAO/IAEA) Food and Agriculture Organization/International Atomic Energy Agency. 2017b. Guideline for packing, shipping, holding and release of sterile flies in area-wide fruit fly control programmes. J. L. Zavala-López, and W. R. Enkerlin (eds.). Food and Agriculture Organization of the United Nations. Rome, Italy. $155 \mathrm{pp}$.

(FAO/IAEA) Food and Agriculture Organization/International Atomic Energy Agency. 2018. Trapping guidelines for area-wide fruit fly programmes. Second edition. W. R. Enkerlin, and J. ReyesFlores (eds.). Rome, Italy. 65 pp.

Gil, L. 2016. Dominican Republic uses nuclear technology to win war against fruit flies. 25 November 2016. Office of Public Information and Communication. IAEA, Vienna, Austria.

Piñero, J. C., W. Enkerlin, and N. D. Epsky. 2014. Recent developments and applications of bait stations for Integrated Pest Management of tephritid fruit flies, pp. 457-492. In T. Shelly, N. Epsky, E. B. Jang, J. Reyes-Flores, and R. Vargas (eds.), Trapping and the detection, control, and regulation of tephritid fruit flies. Springer Science \& Business Media, Dordrecht, The Netherlands.

Programa Moscamed-RD. 2017. Informes semanales 2015-2017 del Programa Moscamed-RD al Ministerio de Agricultura. Santo Domingo, República Dominicana.

Programa Regional Moscamed. 2012. Manual del sistema de detección por trampeo de la mosca del Mediterráneo (Ceratitis capitata, Wied). SAGARPA-MAGA-USDA, February 2012. Ciudad de Guatemala, Guatemala. 24 pp. 